\title{
Refractory Oral Cavity Squamous Cell Carcinoma
}

National Cancer Institute

\section{Source}

National Cancer Institute. Refractory Oral Cavity Squamous Cell Carcinoma. NCI

Thesaurus. Code C148384.

Oral cavity squamous cell carcinoma that does not respond to treatment. 